\title{
NHS England aims to increase transparency
}

$\mathrm{T}$ he National Health Service (NHS) in England is consulting the public on proposals to increase transparency and better manage conflicts of interest. One proposal in particular, requiring NHS consultants (senior physicians) to disclose earnings from the private sector, has raised concerns among some physicians and medical societies.

In its announcement of the launch of the public consultation, which ends Oct. 31, the NHS stated that the proposals will help it become "a world leader on managing conflicts of interest." The list of proposals include having NHS consultants disclose gifts from patients worth more than $£ 50$ $(\$ 81)$, decline gifts from suppliers worth more than $£ 6(\$ 9)$ and indicate if their gross earnings from private practice in the previous year was less than $£ 50000$ (\$81 000), less than $£ 100000$ (\$162 000) or more than $£ 100000$.

Sir Malcolm Grant, chairman of NHS England, has stated that the proposals aren't intended to restrict NHS physicians from working in the private sector, but rather to shed light on work that largely goes "under the radar." In blog posts, Grant suggested that managing conflicts of interest in health care is complex but is "fundamentally a question of good judgment supported by due process." He also acknowledged that the NHS benefits from the experience and expertise gained by physicians in their outside work.

When contacted to comment on the transparency proposals, the British Medical Association (BMA) directed $C M A J$ to a statement by Dr. Keith Brent, its consultant committee chair. According to Brent, NHS consultants are "dedicated professionals" who do private work during evenings and weekends as to not interfere with their NHS duties. He also noted that senior NHS staff are already required to disclose substantial conflicts of interest annually.

The Royal College of Surgeons of

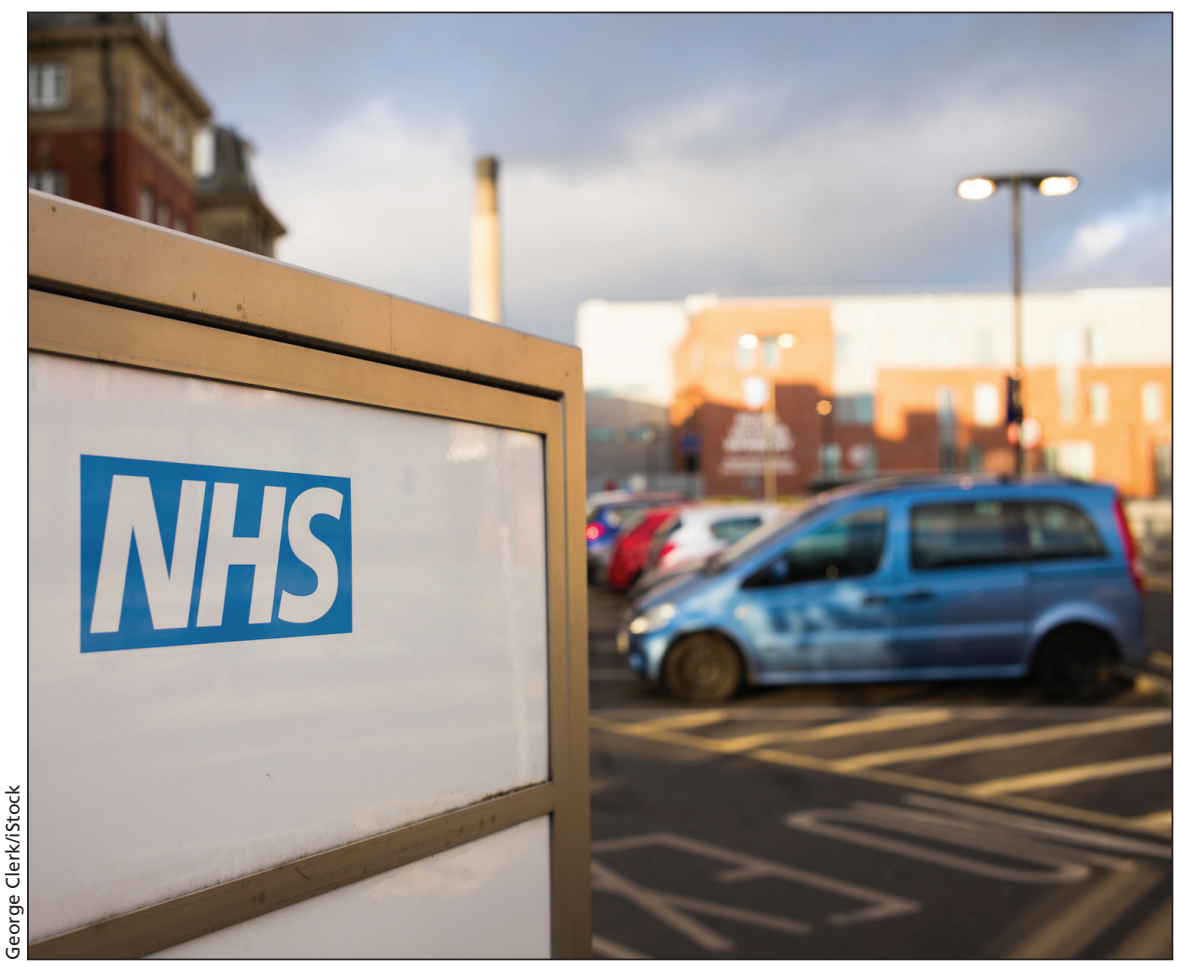

About half of NHS senior physicians also work in the private sector.

England also directed $C M A J$ to a prepared statement on the NHS proposals. The college supports transparency, but finds it "difficult to understand what would be gained from publishing private practice income." The NHS is running the risk of making its physicians feel they can't be trusted, according to the statement.

About half of the 46000 NHS consultants also work in the private sector, supplementing their average NHS earnings of $£ 112000$ (\$181 000) a year. Critics of these physicians worry that senior doctors are shifting their NHS work onto junior doctors and steering patients on waiting lists toward private medicine.

Many physicians disagree that private work affects the NHS, some taking to Twitter to voice their displeasure, suggesting that private work is nothing to be ashamed of, that the doctors who work hardest in the private sector also work the hardest for the NHS, and that the transparency proposals will only push physicians out of the NHS.

It is no surprise that some doctors think it's unnecessary to shed more light on their outside activities, according to Dr. Joel Lexchin, professor emeritus of health policy and management at York University. "Doctors consistently deny that they individually are affected by outside interests but they are not so sure about their colleagues and feel that other doctors may be influenced. This is an example of what's known as cognitive dissonance - a way of justifying your actions," Lexchin said in an email. "As far as doctors splitting their work between the private and public sectors, the potential downside of this is that patients who cannot afford private insurance wait longer because there are fewer people working in the public sector." - Roger Collier, CMAJ

CMAJ 2016. DOI:10.1503/cmaj.109-5341 